\title{
Cardiac troponins and oxidative stress markers in non-pregnant, pregnant and preeclampsia women
}

\author{
Palanisamy Pasupathi ${ }^{1}$, Uma manivannan $^{2}$, Perisamy Manivannan ${ }^{3}$ and Mathiyalagan Deepa ${ }^{1}$ \\ ${ }^{1}$ Institute of Laboratory Medicine, CRISTAL Diagnostic and Research Laboratory (CDRL), Sri Sugam Hospital \\ Campus, Omalur, Salaem 636 455, Tamil Nadu; ${ }^{2}$ Department of Obstetrician \& Gynecology \& ${ }^{3}$ General \\ Medicine \& Diabetologe, Sri Sugam Hospital, Omalur, Salem 636 455, Tamil Nadu, India. \\ e-mail:drppasupathi@gmail.com
}

\begin{abstract}
Free radicals play an important role in the pathogenesis of tissue damage in many clinical disorders, including atherosclerosis. This study was to investigate lipids and oxidative stress markers among women with 50 healthy non-pregnant compare with 50 healthy pregnant and 50 pregnancy-induced hypertensive subjects and correlate with cardiac troponin I (cTnI) and troponin T (cTnT). The level of plasma thiobarbituric acid reactive substances (TBARS), cTnI and cTnT levels significantly increase in pregnancy-induced hypertension compare with other groups. The level of lipids significantly altered in pregnancy-induced hypertension. Conversely, the activities of both enzymatic and non-enzymatic antioxidants were significantly decreased in pregnancy-induced hypertension compared to nonpregnant and healthy pregnant. Our data suggest that there is an imbalance between lipoperoxidation and antioxidants levels during pregnancy and preeclampsia. Serum cTnI and cTnT are elevated in women with pregnancy-induced hypertension indicating some degree of cardiac myofibrillar damage and cardiac dysfunction.
\end{abstract}

\section{Introduction}

Preeclampsia is the leading cause of maternal mortality in developed countries and is associated with a five-fold increase in perinatal mortality; the major cause of fetal compromise is reduced uteroplacental perfusion ${ }^{1}$. Many pathophysiological features of preeclampsia such as increased sensitivity to presser agents, activation of the coagulation cascade and increased vascular permeability suggest that vascular endothelial dysfunction is an important component of this disorder however; the pathogenesis of endothelial disfunction remains unclear. It has been postulated that free radical mediated lipid peroxidation may be involved in this process ${ }^{2}$.

Pregnancy dyslipidemia is associated with an increased risk of preeclampsia. Women with a history of preeclampsia have significant differences in lipid parameters and an increased susceptibility to lipoprotein oxidation when compared with women who had normal pregnancy. Disorders of lipoprotein metabolism are reported to be a major cause of hypertension in preeclampsia ${ }^{3,4}$.
Troponin (cTnI and cTnT) is a constituent of the troponin complex, which regulates the interaction of actin and myosin in striated muscle. Cardiac troponin contains an immunologically distinct Nterminus amino acid chain not expressed in skeletal isoforms. Cardiac troponin is released into the circulation in response to myocardial injury and has been shown to be one of the most sensitive and specific markers of myocardial damage both in ischemic and non-ischemic condition ${ }^{5,6}$.

Lipid peroxides formed at a primary site are then transported through the circulation by lipoproteins causing damage at distant tissues ${ }^{7}$. The endothelial cells lining the high-pressured arterial vessels are particularly vulnerable to oxygen free radical initiated lipid peroxidation. Impaired function of generalized vascular endothelium may, in turn, cause vasospasm and an increase in sensitivity to vasopressors occurring in preeclampsia. Lipid peroxidation is a process determined by the extent of the peroxide-forming free radical mechanisms and the peroxide-removing antioxidative system. It occurs at low levels in all cells and tissues at certain equilibrium. Antioxidants counteract free 
radical disturbances and thereby protect cell membranes against free radical mediated lipid peroxidation. Excesses of free radicals are typically accompanied by increased utilization of antioxidants resulting in a decrease in their concentrations. Moreover, antioxidant activities of superoxide dismutase and glutathione peroxidase and tissue levels of vitamin $\mathrm{E}$ are lower in preeclamptic placenta compared with normal pregnancies ${ }^{8-10}$. This current study, therefore, was aimed at investigating the possible link between the lipids, cardiac markers and oxidative stress markers in pregnancy induce hypertensive women as compared to healthy pregnant and healthy nonpregnant women.

\section{Materials and Methods}

Study population: The population consisted of 150 subjects divided into three groups of women within the age group 19-37 years, of healthy non-pregnant $(n=50)$ compare with health pregnant $(n=50)$ and pregnancy-induced hypertension $(n=50)$ were investigated. The prospective study was carried out at the Sri Sugam Hospital, Salem, Tamil Nadu, India from January 2007 to January 2009. The study was approved by the Human Bioethics Committee (decision SSH/164/2006), and informed verbal consent was obtained from all subjects.

Eligible cases were singleton pregnancies with the diagnosis of preeclampsia. Criteria for the definition of preeclampsia were those of the International Society for the Study of Hypertension in Pregnancy. Preeclampsia was diagnosed in previously normotensive women with two repeat (4 hours apart) diastolic blood pressure measurements of $90 \mathrm{mmHg}$ or greater after the 20th week of gestation $^{11}$. The definition of severe preeclampsia was established if any of the following were present: persistent diastolic blood pressure greater than $110 \mathrm{mmHg}$, elevated transaminase levels (GOT $>40$, GPT $>40)$. No cases or controls had received vitamin supplements or aspirin in the month before enrollment Sample collection and hemolysate preparation: Blood samples were collected by venous puncture in heparinized tubes and the plasma was separated by centrifugation at $\mathrm{x} 1,000 \mathrm{~g}$ for $15 \mathrm{~min}$. After the collection of plasma, the buffy coat was removed and the packed cells were washed thrice with cold physiological saline. A known volume of the erythrocytes was lysed with hypotonic phosphate buffer ( $\mathrm{pH}$ 7.4). The hemolysate was separated by centrifugation at $\mathrm{x} 2,500 \mathrm{~g}$ for $10 \mathrm{~min}$ at $2^{\circ} \mathrm{C}$. Biochemical estimations were carried out immediately.
Biochemical analysis: Biochemical investigation including total cholesterol, triglyceride, HDL-C and LDL-C were determined using fully automated clinical chemistry analyzer (Hitachi 912, Boehringer Mannheim, Germany). Serum VLDL-C was calculated according to Friedewald et $\mathrm{al}^{12}$. Estimation of cTnI level measured by automated immunoassay analyzer (AXSYM System -Abbott Laboratories, Abbott Park, USA). cTnT measured by Roche Elecsys 2010 immunoassay analyzer, USA.

Estimation of lipid peroxidation: Lipid peroxides were estimated by measurement of thiobarbituric acid reactive substances in plasma by the method of Yagi $^{13}$. The pink chromogen produced by the reaction of thiobarbituric acid with malondialdehyde, a secondary product of lipid peroxidation was estimated. The absorbance of clear supernatant was measured against reference blank at $535 \mathrm{~nm}$.

Estimation of enzymic antioxidants: Superoxide dismutase (SOD) was assayed utilizing the technique of Kakkar et $\mathrm{al}^{14}$ based on inhibition of the formation of nicotine amide adenine dinucleotide, phenazine methosulfate and amino blue tetrazolium formazan. A single unit of enzyme was expressed as $50 \%$ inhibition of nitroblue tetrazolium reduction $/ \mathrm{min} / \mathrm{mg}$ protein. Catalase (CAT) was assayed colorimetrically at $620 \mathrm{~nm}$ and expressed as $\mu$ moles of $\mathrm{H}_{2} \mathrm{O}_{2}$ consumed $/ \mathrm{min} / \mathrm{mg} \mathrm{Hb}$ as described by Sinha ${ }^{15}$. The reaction mixture (1.5 $\mathrm{mL}$ ) contained $1.0 \mathrm{~mL}$ of $0.01 \mathrm{M}$ phosphate buffer $(\mathrm{pH} 7.0), 0.1 \mathrm{~mL}$ of hemolysate and $0.4 \mathrm{~mL}$ of $2 \mathrm{M}$ $\mathrm{H}_{2} \mathrm{O}_{2}$. The reaction was stopped by the addition of $2.0 \mathrm{~mL}$ of dichromate-acetic acid reagent $(5 \%$ potassium dichromate and glacial acetic acid were mixed in 1:3). Reduced glutathione (GSH) content was determined by the method of Ellman ${ }^{16} .1 .0 \mathrm{~mL}$ of plasma was treated with $0.5 \mathrm{~mL}$ of Ellmans reagent (19.8 $\mathrm{mg}$ of 5,5'-dithiobisnitro benzoic acid (DTNB) in $100 \mathrm{~mL}$ of $0.1 \%$ sodium nitrate) and 3.0 $\mathrm{mL}$ of phosphate buffer $(0.2 \mathrm{M}, \mathrm{pH} 8.0)$. The absorbance was read at $412 \mathrm{~nm}$. GSH content was expressed as $\mathrm{mg} / \mathrm{dL}$. Glutathione peroxidase (GPx) activity was measured by the method described by Rotruck et $\mathrm{al}^{17}$. Briefly, reaction mixture contained $0.2 \mathrm{~mL}$ of $0.4 \mathrm{M}$ Tris-HCl buffer $\mathrm{pH} 7.0,0.1 \mathrm{~mL}$ of $10 \mathrm{mM}$ sodium azide, $0.2 \mathrm{ml}$ of homogenate (homogenized in $0.4 \mathrm{M}$, Tris- $\mathrm{HCl}$ buffer, $\mathrm{pH}$ 7.0), $0.2 \mathrm{~mL}$ glutathione, $0.1 \mathrm{~mL}$ of $0.2 \mathrm{mM} \mathrm{H}_{2} \mathrm{O}_{2}$. The contents were incubated at $37^{\circ} \mathrm{C}$ for $10 \mathrm{~min}$. The reaction was arrested by $0.4 \mathrm{~mL}$ of $10 \% \mathrm{TCA}$, and centrifuged. Supernatant was assayed for glutathione content by using Ellmans reagent (19.8 $\mathrm{mg}$ of 5,5'-dithiobisnitro benzoic acid (DTNB) in $100 \mathrm{~mL}$ of $0.1 \%$ sodium nitrate). 
Table I: Demographic characteristics of study population in non-pregnant, pregnant and preeclampsia subjects

\begin{tabular}{|c|c|c|c|}
\hline Parameter & $\begin{array}{c}\text { Non-pregnant } \\
\text { women }\end{array}$ & $\begin{array}{c}\text { Normal pregnant } \\
\text { women }\end{array}$ & $\begin{array}{c}\text { Preeclampsia } \\
\text { women }\end{array}$ \\
\hline Mean age (mean $\pm \mathrm{SD}$; years) & $25 \pm 5$ & $28 \pm 9$ & $27 \pm 8$ \\
\hline Weight & $55 \pm 8$ & $65 \pm 5$ & $67 \pm 7$ \\
\hline Body mass index $\left(\right.$ mean $\left.\pm \mathrm{SD} ; \mathrm{Kg} / \mathrm{m}^{2}\right)$ & $23 \pm 3.0$ & $27 \pm 4.6^{* *}$ & $29 \pm 5.3^{\text {cacoca }}$ \\
\hline Hypertension & - & $36(73 \%)$ & $12.5(25 \%)$ \\
\hline Diabetes mellitus & - & $50(100 \%)$ & - \\
\hline Average systolic blood pressure ( $\mathrm{mm}$ of $\mathrm{Hg}$ ) & $120 \pm 2$ & $119 \pm 2^{\mathrm{NS}}$ & $167 \pm 20^{\operatorname{comat}}$ \\
\hline
\end{tabular}

Values are given as mean \pm S.D from 50 subjects in each group; Preeclampsia women compared with non-pregnant women ( $\left.{ }^{\text {cood }} \mathrm{p}<0.001\right)$; * Normal pregnant women compared with non-pregnant women $\left(* * \mathrm{p}<0.01\right.$, NS-Not significant); ${ }^{\dagger}$ Preeclampsia women compared with normal pregnant women $\left({ }^{\ddagger}-\mathrm{p}<0.001\right)$

Table II: Comparison of biochemical changes and cardiac markers in non-pregnant, pregnant and preeclampsia subjects

\begin{tabular}{|c|c|c|c|}
\hline Parameter & $\begin{array}{c}\text { Non-pregnant } \\
\text { women }\end{array}$ & $\begin{array}{c}\text { Normal pregnant } \\
\text { women }\end{array}$ & $\begin{array}{l}\text { Preeclampsia } \\
\text { women }\end{array}$ \\
\hline Total cholesterol (mg/dL) & $154 \pm 12.7$ & $168 \pm 10.5^{\mathrm{NS}}$ & $221 \pm 18.8^{\text {conot }}$ \\
\hline Triglyceride (mg/dL) & $92 \pm 11.5$ & $132 \pm 18^{* *}$ & $252 \pm 22^{\text {and }}$ \\
\hline HDL-cholesterol (mg/dL) & $47 \pm 4$ & $44 \pm 5^{\mathrm{NS}}$ & $34 \pm 7^{\infty \neq \ddagger}$ \\
\hline LDL-cholesterol (mg/dL) & $78 \pm 8$ & $85 \pm 10^{\mathrm{NS}}$ & $138 \pm 13^{\operatorname{arod}}$ \\
\hline VLDL-cholesterol (mg/dL) & $25 \pm 5$ & $39 \pm 6^{*}$ & $50 \pm 5^{\mathrm{bot}}$ \\
\hline Troponin T (ng/mL) & $0.000 \pm 0.000$ & $0.001 \pm 0.00^{\mathrm{NS}}$ & $0.85 \pm 0.03^{\text {and }}$ \\
\hline Troponin I (ng/mL) & $0.000 \pm 0.000$ & $0.01 \pm 0.00^{\mathrm{NS}}$ & $1.02 \pm 0.093^{\mathrm{cod} \neq}$ \\
\hline
\end{tabular}

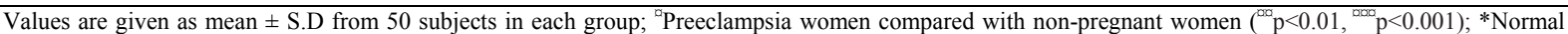
pregnant women compared with non-pregnant women $\left({ }^{*} \mathrm{p}<0.05,{ }^{*} \mathrm{p}<0.01\right.$, NS-Not significant); ${ }^{*}$ Preeclampsia women compared with normal pregnant women $\left({ }^{\ddagger}-\mathrm{p}<0.001\right)$

Table III. Illustrates the level of circulatory lipid peroxidation, antioxidant status in non-pregnant, pregnant and preeclampsia subjects

\begin{tabular}{|c|c|c|c|}
\hline Parameter & $\begin{array}{c}\text { Non-pregnant } \\
\text { Women }\end{array}$ & $\begin{array}{c}\text { Normal pregnant } \\
\text { women }\end{array}$ & $\begin{array}{l}\text { Preeclampsia } \\
\text { women }\end{array}$ \\
\hline TBARS (nmole/mL) & $2.51 \pm 0.21$ & $4.12 \pm 0.35^{*}$ & $6.88 \pm 0.38^{\text {pand }}$ \\
\hline SOD (Unit ${ }^{\mathrm{a}} \mathrm{mg} / \mathrm{Hb}$ ) & $4.21 \pm 0.36$ & $3.24 \pm 0.27 *$ & $2.47 \pm 0.35^{\infty \ddagger}$ \\
\hline CAT (Unit ${ }^{\mathrm{b}} \mathrm{mg} / \mathrm{Hb}$ ) & $70.5 \pm 7.60$ & $58.7 \pm 6.70^{*}$ & $50.4 \pm 6.30^{a x t}$ \\
\hline GPx (Unit $\left.{ }^{\mathrm{c}} \mathrm{mg} / \mathrm{Hb}\right)$ & $8.35 \pm 1.79$ & $6.89 \pm 1.23 *$ & $5.87 \pm 1.55^{\text {and }}$ \\
\hline GSH (mg/dL) & $39.18 \pm 1.67$ & $30.09 \pm 3.14^{*}$ & $27.09 \pm 4.33^{\text {comat }}$ \\
\hline Vitamin A (mg/dL) & $0.97 \pm 0.08$ & $0.65 \pm 0.061^{*}$ & $0.40 \pm 0.067^{0000}$ \\
\hline Vitamin C (mg/dL) & $1.41 \pm 0.21$ & $0.98 \pm 0.13^{*}$ & $0.65 \pm 0.19^{\text {band }}$ \\
\hline Vitamin E (mg/dL) & $1.46 \pm 0.28$ & $1.63 \pm 0.13^{*}$ & $0.73 \pm 0.25^{\text {axa }}$ \\
\hline
\end{tabular}

Values are given as mean \pm S.D from 50 subjects in each group; ${ }^{\circ}$ Preeclampsia women compared with non-pregnant women $\left({ }^{000} \mathrm{p}<0.01,{ }^{, 000} \mathrm{p}<0.001\right) ;{ }^{*}$ Normal pregnant women compared with non-pregnant women $\left({ }^{*} \mathrm{p}<0.001\right)$; ${ }^{\dagger}$ Preeclampsia women compared with normal pregnant women $\left({ }^{\ddagger}-\mathrm{p}<0.001\right)$; A-One unit of activity was taken as the enzyme reaction, which gave $50 \%$ inhibition of NBT reduction $/ \mathrm{min} / \mathrm{mg} \mathrm{Hb}$; B $-\mu$ mol of $\mathrm{H}_{2} \mathrm{O}_{2} \mathrm{consumed} / \mathrm{min} / \mathrm{mg} \mathrm{Hb}$; C $-\mu \mathrm{mol}$ of GSH consumed/min/mg Hb

Estimation of plasma vitamins: Plasma vitamin A ( $\beta$-carotene) was estimated by the method of Bradle and Hombeck ${ }^{18}$. Proteins were precipitated with ethanol and the carotenes were extracted into light petroleum. The intensity of the yellow color due to carotene was read directly at $450 \mathrm{~nm}$ using a violet filter. Vitamin E was measured by the method of Baker et $\mathrm{al}^{19}$ on the basis of the reduction of ferric ions to ferrous ions by vitamin $\mathrm{E}$ ( $\alpha$-tocopherol) and the formation of a red colored complex with 2.2'-dipyridyl at $520 \mathrm{~nm}$. Vitamin C (ascorbic acid) was estimated by the method of Roe and Kuether ${ }^{20}$. 
This involves oxidation of ascorbic acid by copper followed by treatment with 2,4-dinitrophenylhydrazine that undergoes rearrangement to form a product with absorption maximum at $520 \mathrm{~nm}$.

Statistical analysis: All data were expressed as mean \pm SD. The statistical significance was evaluated by Student's t test using Statistical Package for the Social Sciences (SPSS Cary, NC, USA) version 10.0 .

\section{Results}

All the studied groups had similar mean age and mean pregnancy period. Indices of obesity (weight and BMI) were significantly increased in the entire studied group as compared to the control group. Mean blood pressure (systolic and diastolic) was significantly raised in preeclamptic patients compare with pregnant and non-pregnant subjects (Table I).

Table II shown the comparison of biochemical changes and cardiac markers in non-pregnant, pregnant and preeclepsia subjects. Total cholesterol, triglyceride, VLDL, LDL-C and cTnI and cTnT levels were significantly higher in the preeclamptic patients compare with pregnant and non-pregnant subjects but the plasma HDL-C concentrations were much lower in these groups than in the control group. The mean level of lipids and cardiac troponins was statistically significant in preeclampsia women compared with normal pregnant women.

Significant increase in TBARS concentrations was observed in preeclamptic patients compare with pregnant and non-pregnant subjects (Table III). The concentration of TBARS was significantly greater $(p<0.001)$ in preeclampsia women compared with normal pregnant women. The significantly decreased average means level of plasma antioxidant vitamins (vitamin $\mathrm{A}, \mathrm{E}$ and $\mathrm{C}$ ) in preeclampsia subjects as compared to pregnant and non-pregnant women. The activity of enzymic antioxidants like SOD, CAT, GSH and GPx were significantly raised in preeclamptic patients compare with pregnant and non-pregnant subjects. The mean level of erythrocyte antioxidant was statistically significant at $\mathrm{p}<0.001$ in preeclampsia women compared with normal pregnant women.

\section{Discussion}

Lipid peroxidation, a central feature of oxidant stress, may alter membrane integrity and/or membrane-associated functions and can be assessed by a number of methods that include the quantification of either primary or secondary peroxidation end products. Our results increased BMI examined in the present study could partly explain the significant increase in TG and LDL because increase in weight and BMI is associated with increase in body fat percentage levels. It is known that pregnancy-induced hypertension is associated with hypertriglyceridemia. The abovementioned interactions along with increased endothelial triglyceride accumulation may result in endothelial cell dysfunction during gestation. Increased TG, found in pregnancy-induced hypertension, is likely to be deposited in predisposed vessels, such as the uterine spiral arteries and contributes to the endothelial dysfunction, both directly and indirectly through generation of small, dense LDL. Moreover, this hypertriglyceridemia may be associated with hypercoagulability $^{21,22}$.

A significant fall in LDL-C concentration in the control group as observed in this present study may be attributed to hyperoestrogenemia, while LDL-C levels increased significantly in the pregnancyinduced hypertension subjects. Moreover, other studies have also demonstrated that there is a predominance of the atherogenic small LDL and that vascular cell adhesion molecule are increased in association with hyperlipidemia in pregnancyinduced hypertension. The endothelial dysfunction in pregnancy-induced hypertension could originate from oxidative stress as well as dyslipidemia. Many different enzymatic processes can generate free radicals. They are extremely reactive and interact with polyunsaturated fatty acids to produce lipid peroxides with a much longer half-life ${ }^{4,23}$.

We have demonstrated that serum cTnI and cTnT levels are elevated in association with hypertension in pregnancy, and that proteinuric hypertension is associated with the highest levels. Due to the established specificity of this isoform of troponin $\mathrm{T}$ and I for cardiac tissue the most likely explanation for these findings is that some degree of myofibrillary damage occurs in association with hypertension in pregnancy. There are no data to suggest that placental production of cTnI occurs and its specificity for cardiac muscle, as distinct from vascular smooth muscle, would militate against this possibility. In addition, we have reported no significant immunoreactivity for cTnI in human placental homogenates $5,6,23$.

The time course of cardiac troponins elevation in association with hypertension in pregnancy is unclear from our data. While the elevated levels reported here for hypertension in pregnancy are similar to those observed in acute congestive cardiac failure, the clinical significance of this for 
the pregnant woman is unknown. It does, however, raise questions for which there are no clear answers concerning optimal short term and long term left ventricular function. Finally, we did not examine the effects of antihypertensive treatment on cardiac troponins levels and cannot comment on the usefulness of serial cardiac troponins measurements in the assessment of treatment response in pregnancy-induced hypertension $^{24}$.

There have been studies, which suggested that endothelial changes in pregnancy-induced hypertension pathophysiology might be related to either an increase or a decrease in the synthesis of nitric oxide (NO). The NO and MDA levels may possibly be related to the pathogenesis of pregnancy-induced hypertension because, dysfunction of endothelial cells can contribute to inappropriate vasoconstriction and platelet aggregation which are early signs of atherosclerosis, hypertension and coronary vasospasm. Evidence indicates that $\mathrm{NO}$ can have either a pro-oxidant or an antioxidant effect on lipid peroxidation, depending on a variety of contingent factors. At relatively high concentra-tions, $\mathrm{NO}$ can attenuate membrane dysfunction and tissue injury, while acting as a reactive oxygen metabolite $\mathrm{e}^{25}$.

TBARS levels reflect oxidative stress and seem to increase in certain complications of pregnancy. In this study, TBARS levels increased both in pregnancy and preeclamptic patients. Increased TBARS levels reflect lipid peroxidation in cells and may suggest decreased enzymatic free radical scavenging capacity in preeclamptic patients. Results of the present study confirm increased oxidative stress during normal pregnancy and pregnancy-induced hypertension. Lipid peroxidetion may be an important factor in the pathogenesis of pregnancy-induced hypertension ${ }^{26}$.

Reduced SOD, GSH-Px and CAT are antioxidant enzymes responsible for the defense against oxidative tissue damage. In this study, SOD levels showed a decline in preeclamptic women. Over expression of the antioxidant complex enzyme SOD has been postulated as one of the major mechanisms by which cells counteract the deleterious effects of ROS and protect themselves from oxidative damage and, in $\mathrm{PE}$, could play a protective role against initial peroxidation processes. Nevertheless, analysis of molecular mechanisms linked to antioxidant response, which did not form part of the present study, may provide mechanistic clues to the activation of antioxidant defense systems in normal and PE pregnancies ${ }^{3,27}$. Our results are consistent with the literature as GSH-Px is concerned. In the study mentioned, CAT levels decreased in preeclamptic patients when compared with the healthy pregnancy and control group. This might result from elevated free radicals suppressing GSH-Px and CAT activities in patients with preeclampsia. $\mathrm{XO}$ is an integral mediator of reactive oxygen species generation.

Plasma antioxidant activities alter progressively throughout pregnancy as mentioned earlier. Our present study was an attempt to evaluate its correlation with the etiology of preeclampsia. Antioxidant vitamins, with the ability to stabilize highly reactive free radicals, act as the first line of defense against free radical attack and lipid peroxidation. Vitamins $\mathrm{E}(\propto$-tocopherol) and $\mathrm{C}$, have differences in the contribution they make to antioxidant potential, as vitamin $\mathrm{E}$ is the major lipid soluble chain-breaking antioxidant in cell membranes while vitamin $\mathrm{C}$ is an important aqueous phase antioxidant. Antioxidants may act synergistically, for instance, when vitamin $\mathrm{C}$ regenerates $\propto$-tocopherol from the tocopherol radical this 'sacrificial' antioxidant acts more by sparing vitamin $\mathrm{E}$ than by recycling. The important role of vitamin $\mathrm{C}$ in preeclampsia, suggest that changes in its concentration may influence susceptibility of vascular endothelium to oxygen toxicity. Thus, our present study on vitamin $\mathrm{C}$ concentration may provide a means of assessing the total capacity of the chain-breaking antioxidants to prevent lipid peroxidation in plasma and it might be important to evaluate the effectiveness of potential antioxidant defense systems in limiting scale. This study, further, provides evidence for the relationship between plasma vitamin $\mathrm{C}$ levels during the pregnancy and preeclampsia ${ }^{27}$. Our study indicates that normal pregnant women had markedly reduced enzymic and non-enzymic antioxidants as compared to non-pregnant controls. Further decrease was observed in pregnancyinduced hypertension patients when compared to normal pregnants. Our findings exhibits markedly increased levels of lipid peroxidation and significantly decreased levels of antioxidants are important factor in the pathogenesis of pregnancyinduced hypertension.

In conclusion, the findings suggest that significant increase in cardiac markers, lipid peroxidation with diminished level of enzymatic and non-enzymatic antioxidants are responsible for the pathogenesis of pregnancy-induced hypertension.

\section{References}

1. Bellany L, Casas JP, Hingorani AD, Williams DJ. Preeclampsia and risk of cardiovascular disease and cancer in later life: Systematic review and metaanalysis. Br Med J. 2007; 335: 974-79. 
2. Solomon CG, Seely EW. Hypertension in pregnancy: A manifestation of the insulin resistance syndrom? Hypertension 2001; 37: 232-39.

3. Llurba E, Gratacos E, Martín-Gallan P, Cabero L, Dominguez C. A comprehensive study of oxidative stress and antioxidant status in preeclampsia and normal pregnancy. Free Radi Biol Med. 2004; 37: $557-$ 70 .

4. De J, Mukhopadhyay AK, Saha PK. Study of serum lipid profile in pregnancy induced hypertension. Indian J Clin Biochem. 2006; 21: 165-68.

5. Fleming SM, O'Gorman T, Finn J, Grimes H, Daly K, Morrison JJ. Cardiac troponin I in preeclampsia and gestational hypertension. BJOG. 2000; 107: 1417-20.

6. Joyal D, Leya F, Koh M, Besinger R, Ramana Ravi, Kahn S, Jeske W, Lewis B, Steen L, Mestril R, Arab D. Troponin I levels in patients with preeclampsia. Am J Med. 2007; 120.

7. Chen K, Thomas SR, Keaney JF. Beyond LDL oxidation: ROS in vascular signal transduction. Free Radic Biol Med. 2003; 35: 117-32.

8. Caniggia I, Winter J, Lye SJ, Post M. Oxygen and placental development during the first trimester: implications for the pathophysiology of preeclampsia. Placenta 2000; 21: S25-S30.

9. Many A, Hubel CA, Fisher SJ, Roberts JM, Zhou Y. Invasive cytotrophoblasts manifest evidence of oxidative stress in preeclampsia. Am J Pathol. 2000; 156: 321-31.

10. Sharma JB, Sharma A, Bahadur A, Vimala N, Satyam A, Mittal S. Oxidative stress markers and antioxidant levels in normal pregnancy and preeclampsia. IJGO. 2006; 94: 23-27

11. Forest JC, Girouard J, Massé J, Moutquin JM, Kharfi A, Ness RB, Roberts JM, Giguère Y. Early occurrence of metabolic syndrome after hypertension in pregnancy. Obstet Gynecol. 2005; 105: 1373-80.

12. Friedewald WT, Levy RI, Fredrickson DS. Estimation of the concentration of low-density lipoprotein cholesterol in plasma, without use of the preparative ultracentrifuge. Clin Chem. 1972; 18: 499-02.

13. Yagi K. Lipid peroxides and human diseases. Chem Phys Lipids. 1978; 45: 337-51.

14. Kakkar PS, Das B, Viswanathan PN. A modified spectrophotometric assay of superoxide dismutase. Indian J Biochem Biophys. 1984; 21:130-32.

15. Sinha KA. Colorimetric assay of catalase. Anal Biochem. 1972; 47: 389-94.
16. Ellman GL. Tissue sulfhydryl groups. Arch Biochem Biophys. 1959; 82: 70-77.

17. Rotruck JT, Pope AL, Ganther HE, Swanson AB, Hafeman DG, Hoekstra WG. Selenium: Biochemical roles as a component of glutathione peroxidase. Science 1973; 179: 588-90.

18. Bradley DW, Hombeck CL. Clinical evaluation and improved TFA micro method for plasma and serum vitamin (A) $\beta$-carotein. Biochem Med. 1973; 7: 78-86.

19. Baker H, Frank O, De Angelis B, Feingold S. Plasma tocopherol in man at various times after ingesting free or acetylated tocopherol. Nutr Rep Inter. 1980; 21: 531-36.

20. Roe HJ, Kuether CA. Detection of ascorbic acid in whole blood and urine through the 2, 4-dinitrophenylhydrazine derivative of dehydro ascorbic acid. J Biol Chem. 1943; 147: 399- 07.

21. Adegoke OA, Iyare EE, Gbenebitse SO. Fasting plasma glucose and cholesterol levels in pregnant Nigerian Women. Niger Postgraduate Med J. 2003; 10 : 32-36.

22. Gratacos E. Lipid-mediated endothelial dysfunction: A common factor to preeclampsia and chronic vascular disease. Eur J Obstet Gynecol Reprod Biol. 2000; 92: 63-66.

23. Pottecher J, Huet O, Degos V, Bonnet MP, Gaussem P, Duranteau J, Ozier Y, Mignon A, Tsatsaris V. In vitro plasma-induced endothelial oxidative stress and circulating markers of endothelial dysfunction in preeclampsia: an observational study. Hypertens Preg. 2009; 28: 212-23.

24. D'Ischia M, Palumbo A, Buzzo F. Interactions of nitric oxide with lipid peroxidation products under aerobic conditions: Inhibitory effects on the formation of malondialdehyde and related thiobarbituric acidreactive substances. Nitric Oxide. 2000; 4: 4-14.

25. Kumar CA, Das UN. Oxidant stress in preeclampsia and essential hypertension. J Assoc Physicians India. 2002; 50: 1372-75.

26. Patil SB, Kodliwadmath MV, Kodliwadmath SM. Correlation between lipid peroxidation and nonenzymatic antioxidants in pregnancy-induced hypertension. Indian J Clin Biochem. 2008; 23: 45-48.

27. Chappell LC, Seed PT, Kelly FJ, Briley A, Hunt BJ, Charnock-Jones DS, Mallet A, Poston L. Vitamin C and $\mathrm{E}$ supplementation in women at risk of preeclampsia is associated with changes in indices of oxidative stress and placental function. Am J Obstet Gynecol. 2002; 187: 777-84. 